\title{
Anthropometric Assessment of Sub-Cutaneous and Visceral Adipose Tissue in Children and Adolescents from Sofia and Smolyan (Bulgaria)
}

\author{
Zorka Mitova \\ Institute of experimental morphology, pathology and anthropology with museum, \\ Bulgarian Academy of Sciences, Sofia, Bulgaria \\ E-mail:mitovaz@bas.bg
}

Silvia Mladenova

Plovdiv University "Paisiy Hilendarski", affiliate - Smolyan

Doi:10.5901/mjss.2014.v5n1p369

\section{Abstract}

In the medical practice, the assessment of deep (visceral) adipose tissue is made mainly by MRI, computed tomography, densitometry and other methods, which are impossible to use in population studies. The aim of this investigation is to make a comparative anthropometric assessment of the quantity and specific age features in the development of the sub-cutaneous and visceral fat tissue during the time of growth in 9-16-year-old children and adolescents from the capital of the country and Smolyan town (Bulgaria). Analyzed data are part from two complex cross-sectional studies of 9-16-year-old students from Sofia and Smolyan, carried out respectively in the period 2001/2002 and 1998/2001. With a standard anthropometric methodology with each student were measured: height $(\mathrm{m})$ body weight $(\mathrm{kg})$ and waist circumference $(\mathrm{cm})$. The quantities of subcutaneous (SAT) and visceral (VAT) adipose tissue are defined by the regression equations of Brambilla et al. Results showed that between the boys from the two cities, there are no reliable differences in the quantity both of SAT and VAT in all age groups. During puberty growth spurt and after it, the girls from Smolyan have deposited VAT with greater intensity as compared with their Sofia peers. As a result, in the post-puberty age groups, the differences in this index with the girls were statistically reliable, to the benefit of the girls from Smolyan. The comparison of our results with analogous in foreign studies (obtained using the unique for Bulgaria equipment) shows that the referred anthropometric data can be used as a reliable indicator for the ratio between the two components of body fat in the scientific and clinical practice as well.

Keywords: anthropometry; body fat; sub-cutaneous adipose tissue; visceral adipose tissue; adolescents and Bulgaria.

\section{Introduction}

One of the most debated issues in scientific literature is the search for an adequate solution to the problems associated with the precise assessment of the quantity of body fat (BF) in population cohorts studies. The basis for this is the evidence that the amount of BF has a direct link with the predisposition to a number of socially significant diseases whose prevention must begin from the earliest childhood and during adolescence (Borkan et al., 1983; De Lorenzo et al., 1998; Koester et al., 1992; Van Loan, 1996; Fox et al., 2000) In such screening (mass) studies, the evaluation of subcutaneous adipose tissue (SAT) is made relatively easy through the measurement of standard skin fold thickness in certain parts of the body (Bogin and Mac Vean, 1981; Mueller, 1986; Van Loan, 1996; Malina, 1996). Visceral adipose tissue (VAT) is with greater genetic determination, with increased metabolic activity and is directly related to the development of cardiovascular, metabolic and endocrine diseases. With population cohorts research, the measurement of VAT, however, is practically impossible. Such an assessment may be appropriate only in a clinical setting by computer tomography, nuclear magnetic resonance imaging and other costly and not so harmless methods. For these reasons, in a number of scientific studies the strength of the relationships between the individual components of BF with other anthropometric indices for body nutritional status is examined (Goran, 1999; Janssen, 2002; Gordon-Larsen et al., 2003; Brambilla et al., 1994, 2006; Carmienke et al., 2013). Their purpose is to obtain the indirect quantitative assessment and establishment of normal age changes in SAT and VAT which are to serve as the basis for the evaluation and comparison of deviations from the physiological norms. In the scientific literature, there is a range of data about the correlation links of high and very high level, both of the total amount of BF and of SAT and VAT separately with body weight, body mass index (BMI), the amount of skin folds, waist and hip circumference, the waist-hip ratio, the sagital diameter in the 
abdominal area etc. (Slaughter et al., 1988; Malina and Bouchard, 1988; Després et al., 1991; Koester et al., 1992; Bedogni et al., 2003; Carmienke et al., 2013). In foreign literature over the recent years, there have been publications which present the regression equations for anthropometric evaluation not only of BF and SAT, but also of VAT in children and adolescents. The authors prove the presence of racial, ethnic, gender, territorial and health status differences in the deposition and distribution of the two components of body fat (Yanovski et al., 1996; Crespo et al., 2000; Gordon-Larsen et al., 2003; Brambilla et al., 1994, 2006; Carmienke et al., 2013).

In the specialized literature available to us, we did not find anthropometric data about both the development and quantity of the two types of fat tissue (VAT and SAT) during the intensive morphological growth in childhood and adolescent period. This has determined the purpose of this study, namely: to make a comparative anthropometric assessment of the quantity and specific age features in the development of the sub-cutaneous and visceral fat tissue during the time of growth in 9-16-year-old children and adolescents from the capital of the country and Smolyan town (Bulgaria).

\section{Matherial and Methods}

The data analysed are part of two transversal studies of 9-16- year- old students from the cities of Sofia and Smolyan. The study in Smolyan was conducted during the period 1998-2001 (Mladenova, 2003), and in Sofia in 2001-2002 (Mitova, 2009). The first study included 542, and the second - 802 boys and girls with normal body nutritional status defined by Cole et al., 2000 and 2007. The distribution of pupils in age groups was carried out under the following pattern - from age N-1 years and 6 months to over $\mathrm{N}$ years, 5 months and 29 days, with the average age of the pupils examined was in full year age periods, e.g.10 years. With a standard anthropometric methodology (Martin-Saller, 1957) with each student were measured: height $(\mathrm{m})$ body weight $(\mathrm{kg})$ and waist circumference $(\mathrm{cm})$. By the formula Weight $(\mathrm{kg}) / \mathrm{Height}^{2}$ $(\mathrm{m})$ the body mass index (BMI) was calculated. The quantities of subcutaneous (SAT) and visceral (VAT) fat tissue are defined by the regression equations of Brambilla et al., 2006:

SAT $(\mathrm{cm} 2)=14.4 \times \mathrm{BMI}\left(\mathrm{kg} / \mathrm{m}^{2}\right)-329.9$;

VAT $(\mathrm{cm} 2)=1.1 \times$ Waist circumference $(\mathrm{cm})$ - 52.9 .

The objective comparative assessment of age differences is based on the statistical reliability of the quantitative differences of SAT and VAT between adolescents from successive age groups. It is determined by the One-way Analysis of Variance (ANOVA) and Post hoc procedure for multiple comparisons - Scheffe test, whose use is recommended in pair comparisons of samples with different size (Kalinov, 2001). Since the method of Scheffe is conservative, the verification of the test and the analysis of results are carried out at the significance level $p=0.10$.

The reliability of gender differences and the differences between the samples from the two settlements, as of age groups, have been established through Student's test $(p=0.05)$.

The abbreviation "y/a" is used in the text and tabs, it stands for "years of age".

\section{Results}

Fig. 1 and 2 show box plot diagrams with distribution of schoolchildren under the SAT and VAT; fig. 3-6 respectively the age growth curves for boys and girls from both places - in a comparative gender and territorial aspect. Of the fig. 7-14 is represented Scheffe test distribution of the students from Sofia and Smolyan by age and gender samples into homogeneous subsets in accordance with their actual average values of SAT and VAT.

\subsection{SAT- age comparisons (Fig. 3).}

During the research of the respective age period more intensive accumulation of SAT in girls from both cities was registered at the beginning (between 10 and $11 \mathrm{y} / \mathrm{a}$ ) and during the spurt in their teenage development, with a peak between 12 and 13 y/a with the girls from Sofia, and between 12 and 14 y/a with the Smolyan girls. As can be seen from Fig. 1 these are the age stages, during which the variations of SAT are the greatest. Though without much reliability in the age differences in girls (from adjacent age groups) as related to this index, Scheffe test unites the samples in homogeneous subsets with overlapping of the girl samples at the age of 9 and 10;11, 12 and 13; and 14, 15 and 16 (Fig. 7 and 8). Age distribution in homogenous groups of girls from Sofia and from Smolyan correspond to those described in the specialized literature - pre-adolescent, active puberty, including puberty growth spurt (11-13 y/a) and the beginning of post-puberty (14-16 y/a). 
With boys from both cities, the deposition of SAT has a relatively large intensity almost throughout the entire reference period. The age between the 13th and the 14th year, when there is a peak of the puberty growth spurt in their morphological growth, and at the beginning of post-puberty (between 15th and 16th y/a) are an exception. In gender comparisons, Scheffe test registers the differences between the samples of boys in a series of uniform size groups with overlap between them (Fig. 9 and 10). The way in which they overlap illustrates the reliable differences in the quantity of SAT in the samples of every other age group, i.e. between 9-11-13-15 y/a - in Sofia and in 9-11-13-16 y/a - with the boys from Smolyan. Reliable differences between the samples from adjacent age groups concerning SAT were established only in the 14 and 15-year-old boys from Sofia, since their homogeneous groups do not overlap.

In the gender comparisons it has been established that the girls from both places deposit more SAT in comparison with boys. According to the t-Student's test, however, the differences between the sexes as of this index are reliable only for the 11th y/a in Sofia ( $p=0.026)$, and for the 14th and 16th y/a in Smolyan. ( $p=0.001$ and $p=0.022)$.

\subsection{SAT-territorial comparisons (Fig. 5).}

From the 9th to the 16th y/a, the SAT growth curves in boys and girls from both cities cross several times, but almost in all age groups the differences between adolescents from Sofia and Smolyan are unreliable (in both sexes). The only exception is with the 14-year-old Smolyan girls who have a significantly greater amount of SAT compared with their Sofia peers $(p=0.023)$. In this particular case, it is probably a specific feature of the sample of the 14-year old girls from Smolyan, as this trend is not observed in Smolyan girls from the post-puberty age groups.

\subsection{VAT- age comparisons (Fig. 4).}

Like with the SAT, more intensive deposition of VAT in girls from both settlements has been registered at the beginning of the survey period (between the 9th and the 11th y/a), and during the peak in their growth spurt during puberty between the 12th-13th y/a. In this case, Scheffe test shows reliable age differences in Sofia girls from adjacent age groups 9, 10 and $11 \mathrm{y} / \mathrm{a}$ (Fig. 11-12).. This is why the girls from these samples have been distributed in three separate homogeneous groups without overlapping between them. In Smolyan 9-11-year-old girls, the intensity of deposition of VAT is relatively small, and the homogenous size groups in which they are distributed by the test overlap. Despite this, with VAT the age distribution in homogeneous groups of girls from both localities, generally corresponds to the distribution obtained by SAT (pre-adolescence, active puberty and post-puberty).

In boys from Sofia and from Smolyan the deposition of VAT is with a relatively constant intensity over the period examined. Related to this index, Scheffe test differentiates among most of the samples between years 9 and 14, in a series of uniform groups with overlapping illustrating reliable differences between the boys in every other year (Fig. 13 and 14). The only reliable differences between the samples from adjacent VAT age groups have been registered at the beginning (between 10 and 11 y/a) - with Smolyan boys, and at the end of the puberty growth spurt (between 14 and 15 y/a) with the boys from Sofia.

Unlike SAT, the gender comparisons of VAT showed that during the entire period the boys from both places have deposited substantially more VAT in comparison with that of girls, and this trend increases with age. According to Student's t-test the differences between the sexes are reliable throughout most of the age period, with the exception of the 10th and 11th y/a in Sofia (from $p=0.039$ to $p=0.000$ ), and the 14th, 15th and 16th y/a in the Smolyan adolescents $(p=0.000)$.

\subsection{VAT- territorial comparisons (Fig. 6).}

Statistically reliable differences in the quantity of VAT in the surveyed adolescents from Sofia and Smolyan have been observed only in girls. After the 11th y/a the Smolyan girls outpace their Sofia peers in the intensity of deposition of VAT. Unlike SAT, this trend remains stable with age and the girls from Smolyan at post-puberty age (15 and $16 \mathrm{y} / \mathrm{a}$ ) have a reliable greater quantity VAT, in comparison with their peers from the capital.

\section{Discussion}

The comparison of our results with similar data and established age tendencies in foreign literature (obtained using the unique for Bulgaria equipment) showed that the data about the quantity of subcutaneous and visceral adipose tissue 
obtained indirectly, through anthropometric methods are reliable indices that can be used in research and in clinical practice.

Overall, the boys from both studies deposit proportionally greater amounts of VAT, while the girls have a larger quantity of SAT. The age changes and variations of SAT and VAT in the students surveyed by us match the literary data on «physiological» changes in fat tissue as one of the main components of body composition related to age and sex during puberty development (Grundy, 1989; Brook, 1995; Petrova, 2000).

The results obtained confirm the fact that the second maximum in BF deposition coincides with the beginning of the intensive morphological growth (between 10 and $11 \mathrm{y} / \mathrm{a}$ ), which according to a number of authors is a reserve of energy for the upcoming puberty growth spurt (Hassink, 1996; Kratzsch, 1997; Stanimirova, 2007; Petrova, 2000).

The relative decrease of the intensity of deposition of SAT and VAT between the 11th and 12th y/a for girls and between the 13th and the 14th y/a for boys corresponds to the literary data for decrease of $\% \mathrm{BF} /$ percent body fat/ during the peak in the morphological growth spurt during puberty (Paige, 1986; Amador et al., 1992; Petrova, 2000).

\section{Conclusion}

The comparative anthropometric evaluation of the amount of subcutaneous and visceral fat tissue in 9-16 year- old students from Sofia and Smolyan showed that with the boys from the two cities, there are no reliable differences in the quantity both of SAT and VAT in all age groups.

During puberty growth spurt and after it, the girls from Smolyan have deposited VAT with greater intensity as compared with their Sofia peers. As a result, in the post-puberty age groups, the differences in this index with the girls were statistically reliable, to the benefit of the girls from Smolyan.

Overall, the boys from both studies deposit proportionally greater amounts of VAT, while the girls have a larger quantity of SAT. The age changes and variations of SAT and VAT in the students surveyed by us match the literary data on «physiological» changes in fat tissue as one of the main components of body composition related to age and sex during puberty development.

The results obtained confirm the fact that the second maximum in fat tissue deposition coincides with the beginning of the intensive morphological growth (between 10 and $11 \mathrm{y} / \mathrm{a}$ ), which represent a energy reserve for the upcoming puberty growth spurt.

The relative decrease of the intensity of deposition of SAT and VAT between the 11th and 12th y/a for girls and between the 13th and the 14th y/a for boys corresponds to the literary data for decrease of $\% \mathrm{BF}$ during the peak in the morphological growth spurt during puberty.

For further clarification of the age-sex regularities in the development of the SAT and VAT during growth it is necessary to process the data of socio-demographic factors as well as to collect additional information concerning nutrition, dietary habits and physical activity of children and adolescents from both localities.

\section{Acknowledgments}

This work was supported by the European Social Fund and Republic of Bulgaria, Operational Programme "Human Resources Development” 2007-2013 framework, Grant №BG051PO001-3.3.06-0048 from 04.10.2012.

\section{References}

Amador, M., J. Bacallao and M. Hermelo (1992): Adiposity and growth: relationship of stature at fourteen years with relative body weight at different ages and several measurements of adiposity and body bulk. Eur. J. Clin. Nutr. 46: 213-219.

Bedogni G, lughetti L, Ferrari M, Malavolti M, Poli M, Bernasconi S et al. (2003): Sensitivity and specificity of body mass index and skinfold thicknesses in detecting excess adiposity in children aged 8-12 years. Ann. Hum. Biol., 30: 132-139.

Bogin, B. \& R. Mac Vean (1981): Nutritional and biological determinants of body fat patterning in urban Guatemalan children. Hum. Biol. 53: 259-268.

Borkan, G., D. Hults, S. Gerzof, B. Burrows and A. Robbins (1983): Relationships between computed tomography tissue areas, thicknesses and total body composition. Ann. Hum. Biol. 10: 537-546.

Brambilla P, Manzoni P, Sironi S, Simone P, Del Maschio A, di Natale B et al. (1994): Peripheral and abdominal adiposity in childhood obesity. In.t J. Obes., 18: 795-800.

Brambilla, P., G. Bedogni, L.A. Moreno, M.. Goran, B. Gutin, K.R. Fox, D.M. Peters, P. Barbeau, M. De Simone and A. Pietrobelli (2006): Crossvalidation of anthropometry against magnetic resonance imaging for the assessment of visceral and subcutaneous adipose tissue in children. Int. J. of Obes., 30: 23-30. 
Brook, C. (1995): The fat child. In: Brook, C. (Ed.): Paediatric Endocrinology. Blackwell Science Ltd, Cambridge: 210-233.

Carmienke, S., M.H. Freitag, T. Pischon, P. Schlattmann, T. Fankhaenel, H. Goebel and J. Gensichen (2013): General and abdominal obesity parameters and their combination in relation to mortality: a systematic review and meta-regression analysis.Epid. Europ. J. of Clin. Nutr., 67: 573-585.

Cole T, M. Bellizzi, K. Flegal and W. Dietz (2000): Establishing a standard definition for child overweight and obesity: international survey. BMJ, 320: 1240-1243.

Cole T., K. Flegal, D. Nicholls and A. Jackson (2007): Body mass index cut offs to define thinness in children and adolescents: international survey. BMJ, 335: 194-201.

Crespo, C.J., E. Smit, R.E. Andersen, O. Carter-Pokras, B.E. Ainsworth (2000): Race/ethnicity, social class and their relation to physical inactivity during leisure time: results from the Third National Health and Nutrition Examination Survey, 1988-1994. Am. J. Prev. Med:;18: 46-53.

De Lorenzo, A., I. Bertini, N. Candeloro, L. Iacopino, A. Andreoli and M. Van Loan. (1998): Comparison of different techniques to measure body composition in moderately active adolescents. Br. J. Sports Med. 32: 215-219.

Despres, J., D. Prudhomme, M. Pouliot, A. Tremblay and C. Bouchard (1991): Estimation of deep abdominal adipose tissue accumulation from simple anthropometric measurements in men. Am. J. Clin. Nutr. 54: 471-477.

Fox, K.R, D.M. Peters, P. Sharpe, M.Bell (2000): Assessment of abdominal fat development in young adolescents using magnetic resonance imaging. Int J Obes Relat Metab Disord; 24: 1653-1659.

Goran, M.I. (1999):Visceral fat in prepubertal children: influence of obesity, anthropometry, ethnicity, gender, diet and growth. Am J Hum Biol., 11: 201-207.

Gordon-Larsen, P., L.S. Adair, B.M. Popkin (2003): The relationship of ethnicity, socioeconomic factors, and overweight in U.S. adolescents. Obes. Res., 11: 121-129.

Grundy, 1989 Grundy, S., J. Barnett and L. Reinken (1989): Obesity. In: Eichenwald, H. and Decker, B. (Eds.): Current Therapy in Pediatrics. Inc. Toronto, Philadelphia: 179-181.

Hassink, S., D. Sheslow, E. de-Lancey, I. Opentanova, R. Considine and J. Caro (1996): Serum leptin in children with obesity: relationship to gender and development. Pediatrics. 98(1): 201-203.

Janssen, I., S.B. Heymsfield, D.B. Allison, D.P. Kotler, R. Ross (2002): Body mass index and waist circumference independently contribute to the prediction of nonabdominal, abdominal subcutaneous and visceral fat. Am. J. Clin. Nutr., 75: 683-688.

Kalinov, K. (2001): Statistical methods in behavioral and social sciences. Sofia, New Bulgarian University: 232-275 (in Bulgarian).

Koester, R., G. Hunter, S. Snyder, M. Khaled and L. Berland (1992): Estimation of computerized tomography derived abdominal fat distribution. Int. J. Obes. Relat. Metab. 16: 543-554.

Kratzsch, J., B. Dehmel, F. Pulzer, E. Keller, P. Englaro, W. Blum and M. Wabitsch (1997): Increased serum GHBP levels in obese pubertal children and adolescents: relationship to body composition, leptin and indicators of metabolic disturbances. Int. J. Obes. Relat. Metab. Disord. 21(2): 1130-1136.

Malina, R. (1996): Regional Body Composition: Age, Sex, and Ethnic Variation. In: Roche, A. Heymsfield, S. and Lohman, T. (Eds.): Human Body Composition. Human Kinetics: 217-255.

Malina, R. and C. Bouchard (1988): Subcutaneous fat distribution during growth. In: Bouchard C. and Johnston F. (Eds.): Fat distribution during growth and later health outcomes. New York Plenum: 63-84

Martin, R., and K. Saller (1957): Lehrbuch der Anthropologie in sistematischer Darstellung Stuttgart, Gustav Fischer Verlag: 308-385.

Mitova, Z. (2009): Anthropological characteristics of physical development, body composition and nutritional status in 9-15-year-old children and adolescents from Sofia. PhD thesis, Sofia (in Bulgarian).

Mladenova, C. (2003): Anthropological characteristics of growth and development of children and adolescents from Smolyan region in modern conditions of life. PhD thesis, Plovdiv (in Bulgarian).

Muller, W. (1986): Environmental sensitivity of different skin fold sites. Hum. Biol., 58: 499-506.

Paige, D. (1986): Obesity in childhood and adolescence. Postgr. Med. 79(1): 233-245.

Petrova, C. (2000): Quantity and distribution of fat mass in childhood obesity and their importance for the later complications. PhD, Sofia (in Bulgarian).

Slaughter, M., T. Lohman, R. Boileau, C. Horswill, R. Stillman, M. van Loan, and D. Bemben (1988): Skinfolds equations for estimation of body fatness in children and youth. Hum. Biol. 60: 709-723.

Stanimirova, N., L. Peneva, Z. Baltova. (2007): Physical and pubertal development of Bulgarian children aged 0 to 18 years: Standards curves. Novo Nordisk, Sofia, 1-118 (in Bulgarian).

Van Loan, M. (1996): Total body composition: Birth to old age. In: Roche, A., Heymsfield, S. and Lohman, J. (Eds.): Human body composition. Human Kinetics, 205-215.

Yanovski, J.A., S.Z. Yanovski, K.M. Filmer, V.S. Hubbard, N. Avila, B. Lewis et al. (1996): Differences in body composition of black and white girls. Am. J. Clin. Nutr., 64: 833-839. 


\section{Apendix}

Fig. 1 and 2: Box plot diagrams of the distribution under the SAT and VAT in schoolchildren by age, sex and territorial groups
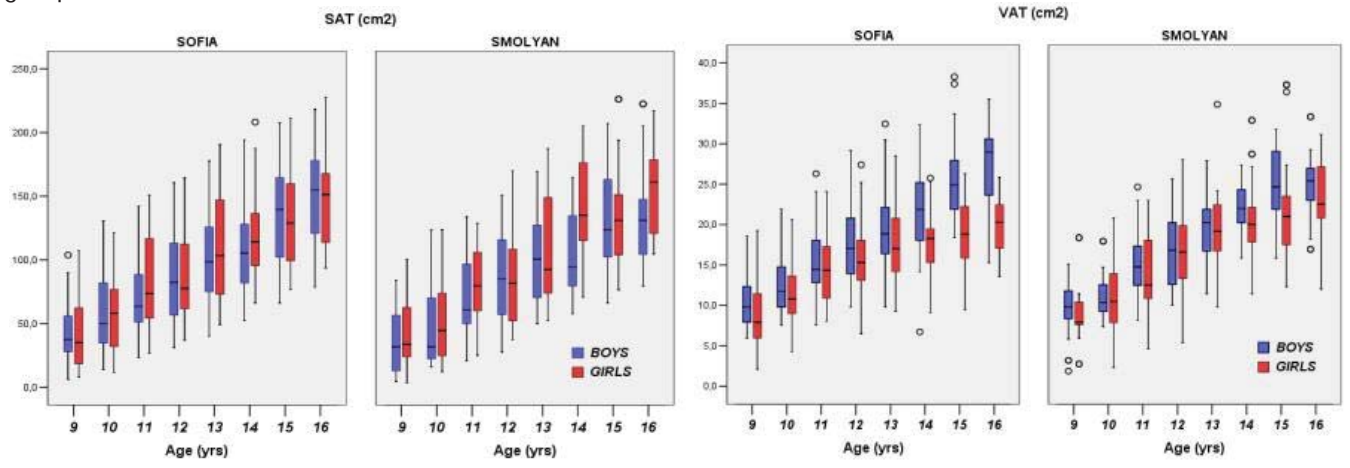

Fig. 3 and 4: Age growth curves of SAT and VAT for boys and girls from both places - in a comparative gender
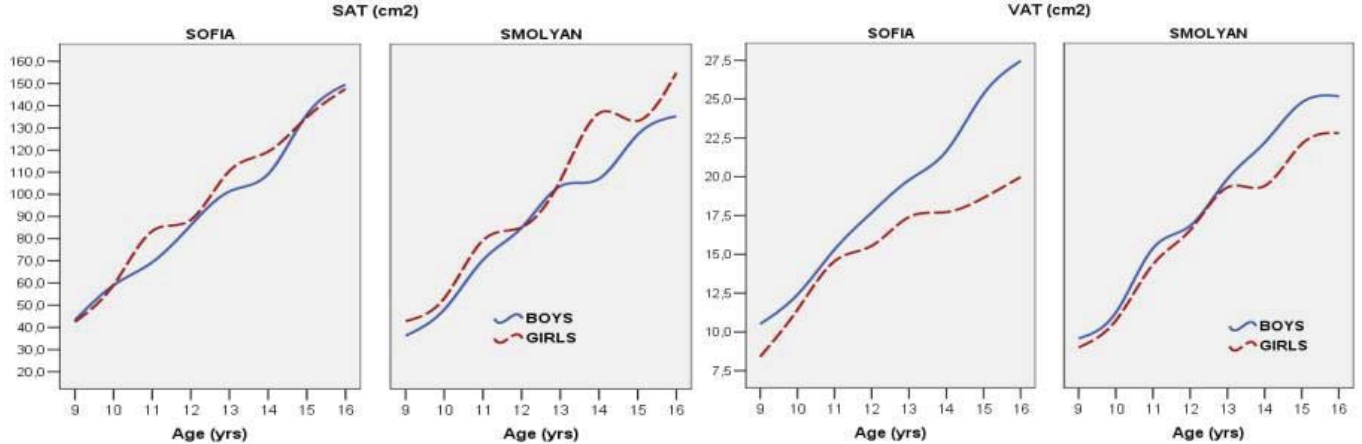

Fig. 5 and 6. Age growth curves of SAT and VAT for boys and girls from both places - in a territorial groups
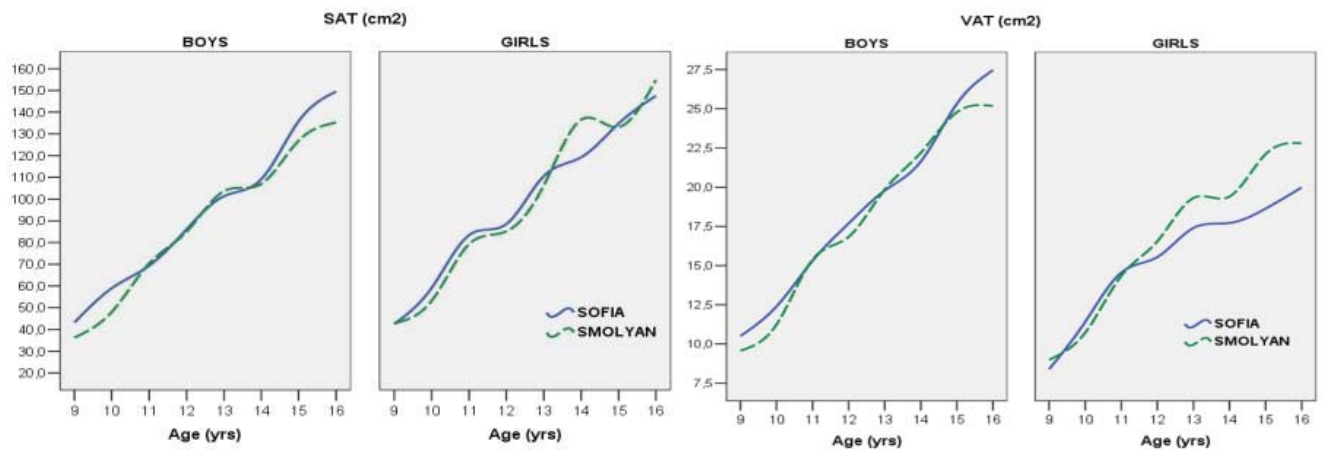

Fig. 7. Means of SAT in Sofia GIRLS $\left(\mathrm{cm}^{2}\right)$

\begin{tabular}{|c|c|c|c|c|c|c|c|}
\hline \multirow{2}{*}{$\begin{array}{l}\text { Age } \\
\text { (y/a) }\end{array}$} & \multirow{2}{*}{$N$} & \multicolumn{4}{|c|}{ Homogeneous subsets } & \multirow[b]{2}{*}{5} & \multirow[b]{2}{*}{6} \\
\hline & & 1 & 2 & 3 & 4 & & \\
\hline 9 & 37 & 42.5 & & & & & \\
\hline 10 & 56 & 59.1 & 59.1 & & & & \\
\hline 11 & 56 & & 83.4 & 83.4 & & & \\
\hline 12 & 59 & & & 88.5 & 88.5 & & \\
\hline 13 & 62 & & & & 110.6 & 110.6 & \\
\hline
\end{tabular}




\begin{tabular}{ll|ll}
14 & 60 & 119.3 & \\
15 & 53 & 134.7 & 134.7 \\
16 & 26 & & 147.5 \\
\hline \multicolumn{2}{l}{ Scheffe test at $\boldsymbol{p}=\mathbf{0 . 1 0}$}
\end{tabular}

Fig. 8. Means of SAT in Smolyan GIRLS $\left(\mathrm{cm}^{2}\right)$

\begin{tabular}{lllllll}
\hline Age & \multirow{2}{*}{ (y/a) } & \multicolumn{6}{l}{ Homogeneous subsets } \\
\cline { 3 - 6 } & $\mathbf{1}$ & $\mathbf{2}$ & $\mathbf{3}$ & $\mathbf{4}$ & $\mathbf{5}$ \\
\hline 9 & 19 & 42.8 & & & & \\
10 & 36 & 53.2 & 53.2 & & & \\
11 & 24 & & 79.2 & 79.2 & & \\
12 & 36 & & 85.2 & 85.2 & & \\
13 & 30 & & & 106.3 & 106.3 & \\
15 & 37 & & & & 133.1 & 133.1 \\
14 & 37 & & & & 136.5 & 136.5 \\
16 & 44 & & & & & 154.8 \\
\hline
\end{tabular}

Scheffe test at $p=0.10$

Fig. 9. Means of SAT in Sofia BOYS $\left(\mathrm{cm}^{2}\right)$

\begin{tabular}{lllllll}
\hline $\begin{array}{l}\text { Age } \\
\text { (y/a) }\end{array}$ & $\boldsymbol{N}$ & \multicolumn{5}{l}{ Homogeneous subsets } \\
\hline 9 & 37 & $\mathbf{1}$ & $\mathbf{2}$ & $\mathbf{3}$ & $\mathbf{4}$ & $\mathbf{5}$ \\
\hline 9 & 37.2 & & & & \\
10 & 56 & 59.0 & 59.0 & & & \\
11 & 56 & & 69.4 & 69.4 & & \\
12 & 55 & & & 86.1 & 86.1 & \\
13 & 58 & & & & 101.3 & \\
14 & 53 & & & & 109.2 & \\
15 & 58 & & & & 135.9 \\
16 & 20 & & & & 149.5 \\
\hline \multicolumn{5}{l}{ Scheffe test at $\boldsymbol{p}=\mathbf{0 . 1 0}$}
\end{tabular}

Fig. 10. Means of SAT in Smolyan BOYS $\left(\mathrm{cm}^{2}\right)$

\begin{tabular}{|c|c|c|c|c|c|c|c|}
\hline Age & $N$ & Hom & geneol & s subs & & & \\
\hline (y/a) & & 1 & 2 & 3 & 4 & 5 & 6 \\
\hline 9 & 38 & 36.2 & & & & & \\
\hline 10 & 26 & 48.1 & 48.1 & & & & \\
\hline 11 & 27 & & 70.4 & 70.4 & & & \\
\hline 12 & 36 & & & 85.0 & 85.0 & & \\
\hline 13 & 41 & & & & 103.6 & 103.6 & \\
\hline 14 & 37 & & & & 107.0 & 107.0 & 107.0 \\
\hline 15 & 38 & & & & & 126.9 & 126.9 \\
\hline 16 & 37 & & & & & & 135.2 \\
\hline
\end{tabular}

Fig. 11. Means of VAT in Sofia GIRLS $\left(\mathrm{cm}^{2}\right)$

\begin{tabular}{lllllll}
\hline Age & \multirow{N}{*}{ (y/a) } & $\boldsymbol{N}$ & \multicolumn{5}{l}{ Homogeneous subsets } \\
\cline { 3 - 6 } & & $\mathbf{1}$ & $\mathbf{2}$ & $\mathbf{3}$ & $\mathbf{4}$ & $\mathbf{5}$ \\
\hline 9 & 37 & 8.4 & & & & \\
10 & 56 & & 11.4 & & & \\
11 & 56 & & & 14.6 & & \\
12 & 59 & & 15.5 & 15.5 & \\
13 & 62 & & & 17.4 & 17.4 \\
14 & 60 & & & 17.7 & 17.7 \\
15 & 53 & & & & & 18.6 \\
16 & 26 & & & & & 20.0 \\
\hline
\end{tabular}

Scheffe test at $p=0.10$ 
Fig. 12. Means of VAT in Smolyan GIRLS $\left(\mathrm{cm}^{2}\right)$

\begin{tabular}{llllll}
\hline $\begin{array}{l}\text { Age } \\
\text { (y/a) }\end{array}$ & $\boldsymbol{N}$ & \multicolumn{4}{l}{ Homogeneous subsets } \\
\cline { 3 - 6 } & & $\mathbf{1}$ & $\mathbf{2}$ & $\mathbf{3}$ & $\mathbf{4}$ \\
\hline 9 & 19 & 9.0 & & & \\
10 & 36 & 10.7 & 10.7 & & \\
11 & 24 & & 14.3 & 14.3 & \\
12 & 36 & & & 16.6 & \\
13 & 30 & & & 19.3 & 19.3 \\
14 & 37 & & & 19.4 & 19.4 \\
15 & 37 & & & & 22.1 \\
16 & 44 & & & & 22.8 \\
\hline
\end{tabular}

Scheffe test at $p=0.10$

Fig. 13. Means of VAT in Sofia BOYS $\left(\mathrm{cm}^{2}\right)$

\begin{tabular}{|c|c|c|c|c|c|c|c|}
\hline \multirow{2}{*}{$\begin{array}{l}\text { Age } \\
\text { (y/a) }\end{array}$} & \multirow{2}{*}{$N$} & \multicolumn{6}{|c|}{ Homogeneous subsets } \\
\hline & & 1 & 2 & 3 & 4 & 5 & 6 \\
\hline 9 & 37 & 10.5 & & & & & \\
\hline 10 & 56 & 12.4 & 12.4 & & & & \\
\hline 11 & 56 & & 15.3 & 15.3 & & & \\
\hline 12 & 55 & & & 17.7 & 17.7 & & \\
\hline 13 & 58 & & & & 19.8 & 19.8 & \\
\hline 14 & 53 & & & & & 21.6 & \\
\hline 15 & 58 & & & & & & 25.3 \\
\hline 16 & 20 & & & & & & 27.5 \\
\hline
\end{tabular}

Fig. 14. Means of VAT in Smolyan BOYS $\left(\mathrm{cm}^{2}\right)$

\begin{tabular}{lllllll}
\hline Age & $\boldsymbol{N}$ & \multicolumn{7}{l}{ Homogeneous subsets } \\
\cline { 3 - 7 } (y/a) & & $\mathbf{1}$ & $\mathbf{2}$ & $\mathbf{3}$ & $\mathbf{4}$ & $\mathbf{5}$ \\
\hline 9 & 38 & 9.6 & & & & \\
10 & 26 & 11.2 & & & & \\
11 & 27 & & 15.4 & & & \\
12 & 36 & & 16.8 & 16.8 & & \\
13 & 41 & & & 19.9 & 19.9 & \\
14 & 37 & & & & 22.2 & 22.2 \\
15 & 38 & & & & & 24.8 \\
16 & 37 & & & & & 25.2 \\
\hline
\end{tabular}

Scheffe test at $p=0.10$ 